\title{
Eficacia del bloqueo pectoral en pacientes sometidas a mastectomía
}

\author{
Guzmán C. ${ }^{1}$, Martínez D. ${ }^{1}$, Ojeda D. ${ }^{1}$, Cisternas P. ${ }^{1}$ \\ 1 Servicio de Anestesiología Clínica Dávila, Santiago, Chile.
}

Introducción: La cirugía de mama se asocia a dolor postoperatorio significativo que puede causar disconfort en los pacientes, prolongación de la estadía hospitalaria e incremento en los costos. Además, se asocia a dolor crónico postoperatorio. Los bloqueos regionales son una alternativa para el manejo analgésico en cirugía de mama y podrían presentar ventajas por sobre la analgesia postoperatoria tradicional con opioides. El Bloqueo Pectoral tipo II (PECSII) es una nueva técnica analgésica que podría minimizar los riesgos asociados al uso de opioides.

Materiales y Métodos: Se realizó un ensayo clínico aleatorizado. Previo aprobación del comité de ética y consentimiento informado firmado, se reclutaron 22 pacientes adultos (de 18 a 65 años), con diagnóstico de cáncer de mama, que fueron sometidos a mastectomía radical y/o parcial con disección axilar. Se excluyeron pacientes con antecedentes de náuseas y vómitos post operatorios, índice de masa corporal mayor a 40, coagulopatía, dolor crónico previo, alergia a anestésicos locales y que no consientan. Los pacientes fueron aleatorizados a dos grupos:

Grupo Control: Analgesia Controlada por Paciente (PCEA) con Morfina endovenosa desde el Intraoperatorio.

Grupo Bloqueo Pectoral: Se realizó un Bloqueo Pectoral tipo II con Levobupivacaína 0,25\% $10 \mathrm{ml}$ en el plano interfascial del músculo pectoral mayor y menor, y $20 \mathrm{ml}$ entre pectoral menor y serrato. Se realizó anestesia general estandarizada en ambos grupos. El outcome primario fue dolor (Escala Visual Análoga) a las 2, 12 y 24 horas posterior a la cirugía. También se evaluó parámetros hemodinámicos en el intraoperatorio, consumo de opioides postoperatorio a las 2, 12 y 24 horas, además la presencia de náuseas y vómitos postoperatorios (NVPO). Se analizó estadísticamente en STATA 13 mediante la comparación de 2 medias con T-Test para el consumo de morfina y análisis de medidas repetidas con ANOVA y ecuaciones de estimación generalizadas en el caso de la Escala visual análoga.

Resultados: No hubo diferencias en las características basales de los dos grupos. La analgesia fue similar en ambos grupos a las 2, 12 y 24 horas $(\mathrm{p}=0,291)$. El grupo PECSII tuvo valores de Presión Arterial Media más bajos durante el intraoperatorio $(\mathrm{p}=0,003)$. El grupo de Bloqueo Pectoral tuvo mayor incidencia de náuseas y vómitos postoperatorios $(p=0,033)$. No hubo diferencias significativas en el consumo de morfina postoperatorio a las 2, 12 y 24 horas.

Conclusión: El uso de Bloqueo Pectoral presentaría ventajas respecto a la analgesia convencional con Opioides en pacientes sometidos a Mastectomía.

https://doi.org/10.25237/congresoclasa2019.59 